\title{
PROCESSOS FORMATIVOS DE UMA PESQUISADORA NEGRA NO CAMPO DA CIBERCULTURA E EDUCAÇÃO: IMPLICAÇÕES E TRAJETÓRIAS
}

Tatiana Santos da Paz ${ }^{1}$

\section{RESUMO}

Esse texto pretende analisar a minha experiência formativa como uma pesquisadora negra que busca relacionar o campo da cibercultura e educação com as discussões sobre as relações étnico-raciais. Como relato de experiência, o escrito se situa na compreensão da biografização enquanto instrumento de (auto)formação, de pesquisa e de intervenção (SOUZA, 2008). O texto apresenta como o racismo estrutural, ao criar representações subalternizadas do que é ser negro, forja nas pessoas com essa identificação racial uma percepção negativa de si que tem sido reconstruída pelas mulheres negras por meio da apropriação de artefatos digitais no cenário contemporâneo. A narrativa revela como esses processos de ressignificação atravessaram minha história de vida e constituíram uma experiência formativa como pesquisadora negra no campo da cibercultura e educação.

PALAVRAS-CHAVE: Cibercultura, educação, relações étnico-raciais, mulheres negras

\section{INTRODUÇÃO}

Historicamente, o cabelo das pessoas negras tem sido desvalorizado como o mais visível estigma da negritude e usado para justificar a subordinação de africanos e africanas. Mais do que a cor, o cabelo tornou-se a mais poderosa marca de servidão durante o período de escravização, que se tornou um símbolo de "primitividade", desordem, inferioridade e não civilização (KILOMBA, 2019).

\footnotetext{
Submetido em: 11/12/2019 - Aceito em: 20/12/2019 - Publicado em: 28/12/2019.

1 Doutora em Educação Brasileira pela Universidade Federal do Ceará. Mestre em Educação e Contemporaneidade - PPGEduC - UNEB. Graduada em Pedagogia pela Universidade do Estado da Bahia. Atua como Professora no Instituto Federal do Ceará e é Pesquisadora integrante do Grupo de Pesquisa Linguagens e Educação em Rede (LER). Como pesquisadora e formadora tem experiência nas áreas de Educação e Cibercultura, com ênfase nas discussões sobre ativismo em rede, autoria, tecnologias mòveis e relações étnicoraciais.
} 
Por meio dessa constatação que inicio a tecer os fios da narrativa que entrelaça os aspectos da minha formação enquanto pesquisadora negra no campo da cibercultura e educação. Os relatos da minha itinerância formativa nesse texto perpassam pela minha experiência como criança negra e as significações que atribuí ao meu cabelo durante com o passar dos anos. São os fios de cabelo crespo os marcadores do início de um processo de formação pessoal que atravessou o meu fazer como professora e pesquisadora e despertou em mim a necessidade de rever os valores coloniais que permeavam as minhas experiências pessoais e acadêmicas.

Minha trajetória pessoal de construção identitária como mulher negra foi e ainda é, muitas vezes, marcada pelo sentimento de inadequação, especialmente no que diz respeito à estética, e se amplia para o campo intelectual. Essa dimensão da construção do olhar da mulher negra sobre si é fundamental nas experiências de sociabilidades afetivas, profissionais, pois afetam diretamente o seu olhar sobre si mesmas, muitas vezes marcado por um lugar de subalternidade.

Ao viver a experiência da transição capilar como mulher negra, iniciada em 2013, encontrei nas redes sociais on-line outras mulheres que estavam vivenciando o mesmo processo, levantando questionamentos e propondo respostas sobre a persistência de uma relação negativa com a estética negra. $\mathrm{O}$ conhecimento desse processo de trocas entre mulheres negras, estabelecido nas plataformas digitais por meio dos seus relatos de experiência, me conduziu a pensar e investigar sobre o que mulheres negras ensinam/aprendem nas redes sociais; como constroem suas narrativas; quais conhecimentos articulam; e o que o processo significa para elas.

A minha itinerância como pesquisadora interessada pelas autorias de mulheres negras no campo da cibercultura e suas implicações para os processos formativos, se origina da estreita relação entre minha história de vida e minha atuação como docentepesquisadora. Esse texto pretende situar a minha experiência formativa como pesquisadora que busca relacionar o campo da cibercultura e educação com as discussões sobre as relações étnico-raciais. 


\section{Revista Docência e Cibercultura}

Este relato de experiência se situa na compreensão biografização como instrumento de (auto)formação, de pesquisa e de intervenção (SOUZA, 2008). Vejo nesse texto a possibilidade formativa de significar a minha história de vida, por meio das marcas e dispositivos experienciados nos contextos da minha formação como pesquisadora que fazem dessa narrativa um relato de experiência e um manifesto acadêmico. Compreende-se neste relato que processos formativos são construídos por diferentes experiências de vida que não estão restritas aos espaços formais de educação e se constituem como um fenômeno de significado mais amplo, global, que inclui diferentes facetas da vida de uma pessoa (BONDÍA, 2002; JOSSO, 2002; DOMINCÉ, 2006; MACEDO, 2010). Considera-se também que as esferas do digital em rede se tornaram campos legítimos de formação, podendo atribuir-se a elas o status de redes educativas, já que a formação acontece em múltiplos contextos (SANTOS, 2011).

$\mathrm{O}$ relato sobre o meu processo formativo como pesquisadora negra situa-se no campo epistemológico dos estudos decoloniais e pós-coloniais, que são aqueles que emergem dos discursos dos subalternizados e seus testemunhos numa sociedade colonial. Como oposição ao discurso colonial, há a necessidade histórica de elaborar estratégias legitimadoras de emancipação, o que demanda uma revisão radical da temporalidade social na qual histórias emergentes possam ser escritas (BHABHA, 2013).

\section{ITINERÂNCIAS FORMATIVAS COMO MULHER NEGRA}

Minhas memórias remontam experiências de rejeição na escola e nos relacionamentos afetivos, que foram sempre acompanhadas de movimentos de resistência. No condomínio onde passei a infância, no Imbuí, um bairro de classe média baixa de Salvador, minha família era uma entre as aproximadamente quatro famílias negras que moravam em um conjunto de 240 apartamentos. Entre as brincadeiras com os amigos e amigas, eu ouvia, principalmente de meninos, apelidos expressos de forma agressiva, como "negresco"; vivenciava situações de ridicularização com o meu cabelo; ou mensagens como: "Essa neguinha aí é feia, eu nunca ia beijar ela não". As falas de inferiorização, também se originavam de meninas brancas que me perguntavam por que meu cabelo era feio e de colegas que não aceitavam ser meu par na quadrilha da escola, por exemplo. 
Essas experiências foram vivenciadas sem a compreensão de um contexto mais amplo que justificasse aquele tipo de violência. Na família, o racismo nunca foi discutido de maneira efetiva por meus pais (homem negro de pele escura e mulher negra de pele clara considerada predominantemente branca pelas pessoas, em Salvador). Apesar de nunca ter debatido essas questões, o racismo era presente minha experiência com a família e os amigos.

Compreendia, ainda criança, que, quando eu ia para Paripe, bairro do subúrbio de Salvador, de maioria negra, onde vive a família do meu pai, sentia-me privilegiada pela minha cor de pele (negra de pele clara). As pessoas muitas vezes me olhavam com admiração e distinção. Porém, na minha escola e no meu bairro, de maioria branca, eu me sentia inferior, principalmente quando a questão era o cabelo crespo.

Nesses espaços, sempre busquei por compensação: nas relações com as amigas do condomínio, sempre fui submissa aos desejos e vontades delas na busca pela aceitação do grupo (atitude que deixou marcas em minha personalidade) e na escola sempre me esforcei para ser excelente aluna, numa tentativa também de ser aceita pelos colegas de turma.

Minha relação com os cabelos perpassava por duas dimensões de preconceito e inferiorização, pois eram curtos e crespos. O padrão de cabelo curto ainda é e era associado a características masculinas. Além disso, a justificativa da minha mãe para cortá-los era que exigia muito esforço para os cuidados e, por isso, só deixaria crescer quando eu tivesse autonomia para mantê-lo arrumado. Portanto, eu carregava uma tripla insatisfação com o meu cabelo: era crespo, curto, e supostamente trabalhoso. Meu sonho, como de muitas outras meninas negras, era que o meu cabelo fosse longo e que eu pudesse balançá-lo.

A solução que me foi apresentada para melhor conviver com os meus cabelos, aos 10 anos, foi o "relaxamento" (alisamento que prometia não retirar totalmente os cachos) e, logo depois, as tranças. Apesar de representarem um símbolo estético-político da cultura africana, as tranças, ainda concretizam, para muitas mulheres negras, a possibilidade de se aproximar de um padrão normativo que é um cabelo com pouco volume, movimento e que "cresce" para baixo. Não tenho recordações na minha infância, mesmo vivendo em Salvador, cidade com 
maior contigente de pessoas negras, de ter visto uma mulher negra com cabelos black power, por exemplo, mesmo circulando em bairros de diferentes níveis socioeconômicos.

Desde os 10 anos, portanto, meu cabelo recebeu produtos químicos de transformação. Inicialmente, minha mãe aplicava os produtos de pouca qualidade em casa, e, posteriormente, passei a frequentar, periodicamente, salões de beleza para modificar os fios (processo denominado na época de "relaxar os cabelos"), que gerava um efeito cacheado. Esses procedimentos eram extremamente custosos economicamente para minha mãe, que fazia esse esforço desproporcional às suas possibilidades financeiras para que eu me sentisse "bem" com a minha estética.

Minhas experiências nesses espaços sempre foram difíceis, pois sabia que, ao entrar no salão, seria alvo de olhares dos profissionais e clientes, que expressavam que meu cabelo daria trabalho na aplicação do produto, e previa sempre que o cabeleireiro iria tocar e desembaraçar meu cabelo com desprezo, sem técnicas apropriadas e que aquilo me causaria muita dor no couro cabeludo. Em diversas ocasiões, saía com o couro cabeludo ferido, devido ao contato da pele com o produto extremamente forte. Porém, eu saía do salão aliviada, sempre muito contente com a possibilidade de diminuir o volume do cabelo e torná-lo menos crespo.

Em alguns momentos, perguntava-me como seria o meu cabelo natural, por que eu não gostava do seu aspecto, e o que aconteceria se um dia acabassem os produtos para cabelo no mundo - como eu sobreviveria a um mundo tão hostil à minha estética? Mas nunca me demorei em tentar encontrar respostas; era mais confortável me manter segundo um padrão.

Aos 25 anos, decidi romper com o processo de relaxamento e adotar o meu cabelo natural. Nesse momento, surgiram as minhas interrogações que deram origem a minha tese de doutorado. A decisão foi construída por muitas perguntas feitas durante o ano de 2014, depois de conversar com uma amiga que decidiu deixar de aplicar químicas transformadoras. Ela tomou essa decisão após ouvir de uma cabeleireira, de forma bem discreta, para que outras clientes não ouvissem, que o cabelo dela não precisava de relaxamento, pois era naturalmente bonito. 
Eu me perguntava: Como, frequentando o mesmo salão, nunca ouvira a mesma opinião de uma cabeleireira? Imediatamente, me respondia: $\mathrm{O}$ cabelo dela era bonito ao natural por ser cacheado e crescer para baixo, mas o meu, por ser crespo e crescer para cima, jamais ficaria bonito. Para cada resposta, eu encontrava novas interrogações: Como cuidar de um cabelo crespo? Por que não relaxar o cabelo? Por que acho meu cabelo feio? Como a história do Brasil ajuda a explicar esse mal-estar com a minha imagem?

As perguntas foram amadurecendo paralelamente ao meu desejo de reconhecer-me negra também pela afirmação da estética natural do meu cabelo. Eu sempre me li como negra e "ser negra" nunca provocou discussões bem definidas sobre as representações atribuídas à minha negritude. $\mathrm{O}$ ano de 2014 foi o período em que passei a morar em Fortaleza e percebi que as pessoas me identificavam muito rapidamente, por ser negra, com olhares de inferiorização ou admiração. Paralelamente, passei a conviver com meu ex-companheiro, branco e europeu, e essa convivência na circulação pela cidade me trouxe mais uma vez a lembrança e a marcação de "mulher negra". Também foi o ano em que passei pela minha transição capilar e nesse período comecei a racionalizar os meus sentimentos de mulher negra. Entendi que as tantas dores e ausências na construção da minha identidade existiam porque eu sou negra!

Nesse momento, os vlogs e blogs foram meu campo de descoberta e pesquisa pessoal. Nas redes, pude ouvir e ler dezenas de histórias como a minha e perceber que a questão com o cabelo era advinda do racismo estrutural, e que meu desconforto estava para além de problemas isolados ou individuais com a autoestima.

Em contato com outras histórias, foi possível reafirmar que o mal-estar com a autoimagem atinge mulheres negras de diferentes idades e lugares sociais e, por isso, para mim, era relevante debater em rede essas questões, afinal, o racismo estrutural, ao criar representações subalternizadas do que é ser negro, forja no sujeito uma percepção negativa de si que, atualmente, tem sido reconstruída pelas mulheres negras no que se refere às representações sobre as nossas estéticas. 
O alcance das ações em rede, das vlogueiras e blogueiras nos seus canais, blogs e nos grupos do Facebook, despertaram-me questionamentos dentro do campo da pesquisa em cibercultura, bem como um ativismo por essa causa protagonizada na atuação como professora do Curso de Pedagogia, enquanto porfessora substituta na Universidade Estadual do Ceará e posterirmente nas Licenciaturas em Química e Letras, como professora efetiva, no Instituto Federal de Edcuação, Ciência e Tecnologia do Ceará. Além disso, durante o doutoramento conheci participei da formação da Rede Nacional de Mulheres Negras Ciberativistas e de outros grupos e coletivos na cidade que buscavam reunir e organizar mulheres negras me diferentes lutas.

\section{ITINERÂNCIAS FORMATIVAS COMO PESQUISADORA NEGRA}

Ao longo do desenvolvimento da minha tese, surgiram também similaridades entre a minha história e de outras mulheres negras, no que diz respeito aos processos criativos e autorais articulados pelas interlocutoras da pesquisa, momento no qual como as nossas itinerâncias estavam imbricadas como mulheres negras, no que diz respeito a busca por uma autoria em meio às dificuldades de perceber-se no lugar de autora, intelectual.

Os relatos de Ana Paula Xongani despertaram em mim a constatação dessas aproximações:

\footnotetext{
Chegou uma época, que eu pensava assim, eu queria fazer vídeo, mas eu não conseguia, eu não gostava, e eu não consegui parar. Então é o lugar do inferno. É o lugar da depressão. Que você não consegue sair, e você não consegue ficar sabe?! Então, a minha maior vitória foi publicar um vídeo e assistir o meu próprio vídeo, sabe?! Ficar satisfeita. (Ana Paula Xongani, trecho de entrevista em outubro de 2017).
}

Por muitas vezes, o texto escrito trouxe o sentimento de medo e a sensação de desconforto com a autoria de uma tese. Os relatos de colegas da pós-graduação, independentemente do recorte racial, traziam esse sentimento: "o medo da folha em branco". No entanto, ao identificar o pouco acesso a autoras negras, invisibilizadas no decorrer do meu processo de escolarização, percebi que esse espaço do texto representava um lugar a ser alcançado, mas também um "não lugar". Enxergar-me autora e assumir a possibilidade de construir algo 
relevante, do ponto de vista acadêmico, tornou-se um desafio no papel de pesquisadora e constituiu um elemento importante para minha formação como pesquisadora.

A escolha desse fenômeno - processos formativos de mulheres negras no YouTube - como campo de estudo é também fruto de uma trajetória de formação profissional tecida por meio de escolhas que revelam que as experiências formativas e as nossas escritas são construídas numa relação estreita entre o que fomos e fizemos e aquilo que queremos ser e fazer. Ao construir a tese eu estive cada vez mai consciente de que as minhas escolhas profissionais, seja na ação docente ou na pesquisa (fazeres imbricados) estavam diretamente entrelaçados com a minha trajetória de vida.

Lélia Gonzalez, ao falar da sua vida, militância e produção intelectual afirmou que o aprofundamento do seu pensamento foi também mediado por sua militância, que a interrelação entre ambas é parte importante no desenvolvimento do seu pensamento, e que a sua própria condição de mulher negra tornou-se elemento importante para o desenvolvimento de suas ideias (BARBOSA, 2010). Há, no pensamento de Lélia, um caminho que nos ajuda a pensar a forma como articulamos a vida, ação política e produção acadêmica, no processo de construção de epistemologias negras. Nesse lugar é que passei a me localizar como pesquisadora.

Os trabalhos de pesquisa que desenvolvi durante a minha itinerância formativa, desde a graduação em Pedagogia na Universidade do Estado da Bahia, versaram sobre temáticas como games e letramento, e tecnologias móveis e autoria. A pesquisa de monografia desenvolvida no curso de Pedagogia, sob a orientação da Professora Doutora Lynn Alves, discutiu acerca do processo de letramento digital de professores do ensino básico em formação continuada que envolveu a interação com o jogo eletrônico Búzios: Ecos da Liberdade, sobre a Revolta dos Búzios, ou Revolta dos Alfaiates, protagonizada pela população negra na Bahia.

Naquele momento da minha trajetória, não havia despertado o desejo pelas questões raciais, apesar de perceber que nos congressos da área de games e cibercultura os negros, e 
principalmente as negras, eram minoria, e sequer ocupavam espaços de poder. Além disso, percebia que a cultura gamer, objeto das minhas pesquisas na graduação, era branca (europeia e norte-americana) e oriental, e isso era debatido à época de forma muito tímida entre desenvolvedores e pesquisadores no Grupo de Pesquisa Comunidades Virtuais. Após a produção do game Búzios, o Grupo de Pesquisa atuou de forma pioneira desenvolvendo jogos eletrônicos que enfatizavam a cultura e o protagonismo da população de descendência africana e indígena na Bahia, como o Jogo 2 de julho, Guardiões da Floresta; Janus; entre outros $^{3}$.

No curso de mestrado, também orientada pela Professora Doutora Lynn Alves, discuti sobre autoria e tecnologias móveis. Nesse momento, eu estava interessada nas possibilidades comunicacionais oferecidas pelos dispositivos móveis conectados em rede, que criavam condições para que crianças de uma escola, localizada na periferia de Salvador, pudessem se envolver em práticas autorias e letramento por meio de imagens e textos que produziam retratos sociais ao narrar o cotidiano. À época, já ensaiava um olhar para a autoria e para o potencial político de narrar o cotidiano em rede e debater sobre diversos temas.

Propor uma pesquisa que reúne um olhar sobre a apropriação do ciberespaço de forma política, por meio de um debate étnico-racial, foi resultado de trajetórias de pesquisa e vida que se encontraram. Essa convergência de campos, no entanto, foi uma oportunidade aproximar no universo da tese áreas que produzem conhecimento a partir de universos epistêmicos que pareciam distantes.

\section{NEGRA PESQUISADORA NO CAMPO DA CIBERCULTURA}

Nesse contexto de conflitos e debates, nasceu o meu posicionamento como pesquisadora que deu origem à minha tese de doutoramento, orientada pelo Professor Doutor Eduardo Junqueira, defendida no Programa de Pós-graduação em Educação Brasileira, na Linha

\footnotetext{
${ }^{3}$ Disponível em: http://comunidadesvirtuais.pro.br/cv/games/\#12. Acesso em: 13 jan. 2017.
} 
Educação Currículo e Ensino, Eixo Tecnologias Digitais e Educação e desenvolvida no Grupo de Pesquisa Linguagens e Educação em Rede (LER).

As narrativas de três mulheres negras, autoras de canais no YouTube, analisadas na pesquisa, estavam centradas na identidade estética das mulheres negras e revelaram a demarcação do corpo como um importante suporte da identidade negra e o cabelo crespo como forte ícone identitário (GOMES, 2002). Ao defender a beleza dos cabelos crespos como transmissão de uma mensagem política de fortalecimento racial e um protesto contra a opressão racial, as narrativas descritas na minha tese de doutorado os indicaram como elementos políticos relevantes neste tempo, e que revela como negociamos políticas de identidade e racismo (KILOMBA, 2019).

Com a escrita da minha tese, inscrevi em minha trajetória de pesquisadora uma demarcação racial proveniente de um aprofundamento do meu olhar sobre o mundo, resultante de uma experiência vivida que sempre perpassou pelas questões étnico-raciais. A minha atuação como pesquisadora implicada em estudos sobre educação e cibercultura na interface com as discussões sobre relações étnico-raciais e de gênero representam para mim um importante lugar político, na medida em que tenho a possibildade de provocar e contribuir com processos de afirmação da história e cultura afrobrasileira e indígena nos currículos escolares e também na produção de artefatos digitais voltados para a educação.

A necessidade por essa demarcação originou-se durante a participação em um evento denominado Encrespa Geral (2014), no qual um ativista do Movimento Negro no Ceará, Bernardo Lamparina, foi palestrante do evento e, em conversa inicial sobre meu desejo de pesquisar a ação de mulheres negras no YouTube, o estudioso (nascido em 1953) colocou sua primeira pontuação sobre o meu futuro trabalho: "Tatiana, em primeiro lugar, você tem que entender que a internet é branca!!!”.

A sua fala, hoje tão óbvia, causou-me o estranhamento inicial da descoberta de algo tão evidente mas que parecia nunca ter impactado os meus olhos. Os primeiros e imaturos questionamentos concentraram-se sobre a ideia de que aquela afirmação poderia invalidar o 


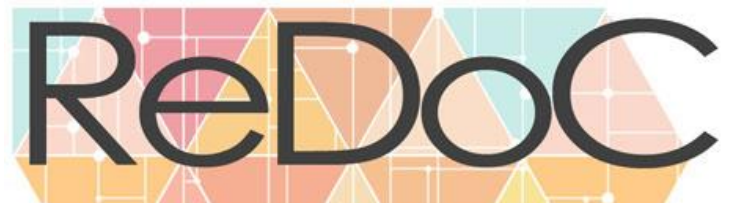

Revista Docência e Cibercultura

aspecto político do fazer de mulheres negras no YouTube. "O que há de político na atuação de mulheres negras em um espaço hegemonicamente branco?’ Depois, acrescentei às minhas interrogações perguntas como: de que maneira o racismo poderia impactar nas práticas comunicacionais e políticas daquelas mulheres numa plataforma predominantemente branca?

As interrogações tornaram-se parte do olhar de pesquisadora na área da educação que se formava, seguidas das constatações construídas por meio da minha experiência nos buscadores do Google Pesquisa e do próprio YouTube. Em pesquisas nessas plataformas, foi possível constatar que a ideia do homem branco europeu universal constava no funcionamento dos códigos, ainda que não fosse possível compreender com base em qual lógica eles operavam.

A ideia do branco como padrão normativo está no contraponto da experiência de mulheres negras, das quais é exigido, o tempo todo, que assim se entendam racializadas no mundo. $\mathrm{Na}$ internet, não é diferente. Mulheres negras, em suas buscas, necessitam usar frequentemente o marcador de gênero e raça, para encontrar conteúdos que contemplem a sua identidade racial.

Na minha tese retratei como, ao inserir, por exemplo, a palavra "maquiagem", no buscador Google, era notável a sub-representação de mulheres negras. Entre as 42 primeiras imagens que apareciam como resultado de busca, apenas uma era de mulher negra. Ainda assim, a imagem carregava um tom de ridicularização sobre essa mulher (PAZ, 2019).

Essas buscas remeteram aos estudos de Grada Kilomba que aponta como as características de homem branco os coloca no topo do poder em suas relações, visto que não são chamados a refletir sobre "ser homem branco", ou seja, não necessita passar por um processo cotidiano de racialização. Sobre as interseções de demarcações de gênero e raça, a autora descreveu em uma de suas palestras: "Uma mulher negra diz que ela é uma mulher negra. Uma mulher branca diz que ela é uma mulher. Um homem branco diz que é uma pessoa”. A pesquisadora ainda destacou que a branquitude, assim como outras identidades que estão no poder, não precisa ser nomeada diariamente. 
[A branquitude] É uma identidade que se coloca no centro de tudo, mas tal centralidade não é reconhecida como relevante, porque é apresentada como sinônimo de humano. [...] E acreditem em mim, não existe uma posição mais privilegiada do que ser apenas a norma e a normalidade. (KILOMBA, 2016).

A ideia do branco como modelo universal da humanidade é tratada nos estudos sobre branquitude que apontam o branqueamento como um processo inventado e mantido pela elite branca, embora considerado, pela mesma elite, como um problema originado entre negros, descontentes e desconfortáveis com a sua condição racial. Porém, o pacto narcísico entre os brancos, ilustrado no modo de funcionamento dos buscadores, revela como a elite faz uma apropriação simbólica que fortalece a autoestima e o autoconceito do grupo branco em detrimento dos demais, e essa apropriação acaba por legitimar suas supremacias econômica, política e social (BENTO, 2014).

Essas experiências revelaram o reforço de imagens e representações negativas que interferem nos processos de identificação individual e construção da identidade coletiva. A interiorização desses processos pode levar à alienação e negação da própria natureza humana para os que nasceram com pele escura, oferecendo-lhes como único caminho de redenção o embranquecimento físico e o cultural, trilhado pela miscigenação e mestiçagem cultural (MUNANGA, 2012).

Nesse sentido, a maioria da população brasileira, negra e branca, introjetou o ideal do branqueamento, que inconsciente não apenas interfere no processo de construção da identidade do ser negro individual e coletivo, como também na formação da autoestima geralmente baixíssima da população negra e na supervalorização idealizada da população branca. (MUNANGA, 2012, p. 11).

O sujeito universal branco está presente nos mecanismos de busca da internet, ainda que não revelem como operam os algoritmos que o gerenciam e ainda que sejam fruto do inputs de seus usuários. Em seu livro, Algoritmos de Opressão: Como Mecanismos de Busca Reforçam o Racismo, Noble (2018) apresenta os resultados de ampla pesquisa sobre algoritmos e representação de mulheres e de mulheres negras no mecanismo de busca do Google. A autora usou telas reais do recurso "autocompletar" do buscador para mostrar como sexismo e misoginia estão presentes nas sugestões do buscador. 
A autora utilizou termos como black girls ou why are Black people so e revela como os mecanismos de busca privilegiam pontos de vista focados em figuras de poder. A hiperssexualização de mulheres negras nos resultados, por exemplo, é fruto de padrões de busca por conteúdos sexuais e pornográficos ligados a mulheres negras. A autora associa os problemas ao uso puramente comercial do Google, bem como à falta de representatividade entre os seus funcionários, aqueles que pensam e operacionalizam a plataforma.

Essas e outras evidências revelam que, ao contrário da crença tecnocrática de que a eliminação do fator humano traria mais clareza e objetividade a processos sensíveis conduzidos por máquinas, observa-se a reprodução de antigos sistemas de desigualdades na relação entre os atores humanos e não humanos. Diante disso, é necessário lançar um olhar para esses fenômenos que considera a identidade étnico-racial como um elemento importante na análise de experiências com a Internet.

A escolha por este campo de estudo expressa o interesse por inserir no debate do campo da Cibercultura outras reflexões epistemológicas, pouco visibilizadas no campo, que refletem, muitas vezes, na área da educação. Pensar sobre uma cultura digital predominantemente branca no campo da educação é refletir sobre os impactos das subrepresentações de pessoas negras e indígenas na construção da autoimagem de crianças com diferentes identificações raciais e suas relações com seus processos formativos. $\mathrm{O}$ apontamento de tais questões interroga a persistência da colonialidade, que sobrevive ao colonialismo e precisa ser revelada e combatida também no campo da cibercultura e educação.

A colonialidade está presente nos materiais didáticos impressos ou digitais, nas imagens reveladas pelas pesquisas nos buscadores, nos autores e autoras mais referenciados nos cursos e escolas, que refletem na autoimagem e aspirações dos sujeitos subalternizados. Essas experiências podem provocar efeitos negativos no que diz respeito à negação do pertencimento racial afrodescendente, que sempre foi estimulada por uma histórica busca pelo ideal de branqueamento da população brasileira (NASCIMENTO, 2011). 
Além disso, no campo da cibercultura e educação é importante também refletir sobre a perspectiva colonizadora comumente vista nas falas dos pesquisadores, ou professores, que buscam "levar a tecnologia para a escola" por meio de um imperativo que não aciona o diálogo. Uma realidade que frequentemente desconsidera as demandas sociais dos sujeitos, suas práticas culturais cotidianas (que muitas vezes permanecem à margem do que é proposto nas escolas), assim como invisibilizam o lugar sociorracial que ocupam, e o sentido da técnica/tecnologia no seu mundo.

\section{CONSIDERAÇÕES FINAIS}

Afirmar-me como mulher negra no campo da cibercultura e educação demarca a busca por enegrecer os diferentes espaços que acessamos como população negra. Refletir sobre como um campo de pesquisa valoriza uma epistemologia centrada no masculino e no branco é um dos desafios para pesquisadoras e pesquisadores da área que de fato se comprometem com a luta antirracista. A preocupação com os processos políticos que envolvem, por exemplo, a participação de mulheres negras nos fóruns de Internet (BLOGUEIRAS NEGRAS, 2019).

A proposta de descolonização em uma área de pesquisa implica conflito, negociações e também produz novas formas de ser, fazer e estar no mundo. A minha busca como pesquisadora é provocar reflexões que gerem processos de inclusão em todas as experiências formativas na perspectiva étnico-racial e além disso, visibilizar do ponto de vista acadêmico e político as estratégias de descolonização que os próprios sujeitos colonizados estão construindo como forma de resistência e existência.

Nesse contexto de luta e afirmação eu tenho vivenciado esse processo formativo como pesquisadora negra. Esse processo passa pelo necessário aprofundamento dos meus estudos e compreensões sobre as relações étnico-raciais no Brasil e constante busca por enegrecer os debates sobre cibercultura no campo da educação. Assim, somam-se a mim outras pessoas negras e indígenas, de diferentes gêneros e orientações sexuais que constroem coletivamente no campo da cibercultura um contexto propício para a consolidação de uma diversidade epistemológica no mundo. Os encaminhamentos dessa trama poderão resultar em novas 
experiências sociorraciais na Internet e com a cultura digital, porém, temos consciência de que o desafio é complexo num contexto em que os processos de plataformização, dataficação e performatividade algorítmica, à serviço do capital, colocam em último plano as ideias de emancipação, liberdade e conhecimento que deram origem à cibercultura.

\section{REFERÊNCIAS BIBLIOGRÁFICAS}

BARBOSA, Lícia. Feminismo negro: notas sobre o debate norte-americano e brasileiro., Anais Fazendo Gênero: Diásporas, Diversidades, Deslocamentos 2010.

BENTO, Maria aparecida Silva. Branqueamento e branquitude no Brasil. In: CARONE, Iray; BENTO, Maria Aparecida Silva. (Org.) Psicologia social do racismo: estudos sobre branquitude e branqueamento no Brasil. Petrópolis: Vozes, 2014.

BHABHA, Homi. O local da cultura. Belo Horizonte: UFMG, 2013.

BLOGUEIRAS NEGRAS. É preciso mais que coragem: a nossa não presença nos Fóruns de Internet, 2019. Texto disponível em: http://blogueirasnegras.org/e-preciso-mais-quecoragem-a-nossa-nao-presenca-nos-foruns-de-internet/. Último acesso em 09 de dezembro de 2019.

BONDÍA, Jorge Larossa. Notas sobre a experiência e o saber de experiência. Revista Brasileira de Educação, Campinas, n. 19, p. 20-28, jan./fev./mar./abr. 2002. Disponível em: http://educa.fcc.org.br/pdf/rbedu/n19/n19a03.pdf. Acesso em: 11 fev. 2016.

DOMINICÉ, Pierre. A formação de adultos confrontada pelo imperativo biográfico. Educação e Pesquisa, São Paulo, v. 32, n. 2, p. 345-357, maio/ago. 2006. Disponível em: http://www.scielo.br/scielo.php?pid=S151797022006000200010\&script=sci_arttext . Acesso em: 4 fev. 2016.

GOMES, Nilma Lino. Corpo e cabelo como ícones de construção da beleza e da identidade negra nos salões étnicos de Belo Horizonte. São Paulo: Faculdade de Filosofia, Letras e Ciências Humanas da Universidade de São Paulo, 2002.

JOSSO, M. C. Experiências de vida e formação. Trad. de José Cláudio e Júlia Ferreira. Lisboa: Educa, 2002.

KILOMBA, Grada. Memórias da plantação: Episódios de racismo cotidiano. Rio de Janeiro: Cobogó. 2019.

MACEDO, Roberto Sidney. Compreender/mediar a formação: o fundante da educação. Brasília: Liber Livro Editora, 2010. 
MUNANGA, Kabengele. Rediscutindo a mestiçagem no Brasil: identidade nacional versus identidade negra. Belo Horizonte: Autêntica, 2012.

NASCIMENTO, A. O Genocídio do Negro Brasileiro. São Paulo: Perspectiva, 2017.

NOBLE, S. Algorithms of Oppression: How Search Engines Reinforce Racism. New York: New York University Press, 2018.

PAZ, T. S. Ativismo em rede e processos formativos decoloniais articulados por mulheres negras no YouTube. Tese de doutorado. Universidade Federal do Ceará, Faculdade de Educação, Programa de Pós-Graduação em Educação Brasileira, Fortaleza, 2019.

SANTOS, Edméa O. A cibercultura e a educação em tempos de mobilidade e redes sociais: conversando com os cotidianos. In: FONTOURA, Helena; SILVA, Marco. (org.). Práticas pedagógicas, linguagem e mídias desafios à pós-graduação em educação em suas múltiplas dimensões. Rio de Janeiro: Anped Nacional, 2011, v. 1, p. 138-160.

SOUZA, Elizeu Clementino de. Memoriais autobiográficos, profissionalização docente e identidade: histórias de vida e formação na pós-graduação. In.: PASSEGGI, M.C.; BARBOSA, T.M. (Orgs.) Memórias, Memoriais: pesquisa e formação docente. Natal: EDUFRN; São Paulo: PAULUS, 2008, pp. 119/133. 